\title{
Associações de agentes humanos e não humanos em perspectiva global na construção da Amazônia brasileira
}

\author{
Associations between human and non-human agents in a global \\ perspective of the construction of the Brazilian Amazon
}

\author{
André Vasques Vital \\ Doutorando, Programa de Pós-graduação em História das Ciências e da Saúde/ \\ Casa de Oswaldo Cruz/Fiocruz. \\ vasques_hist@yahoo.com.br
}

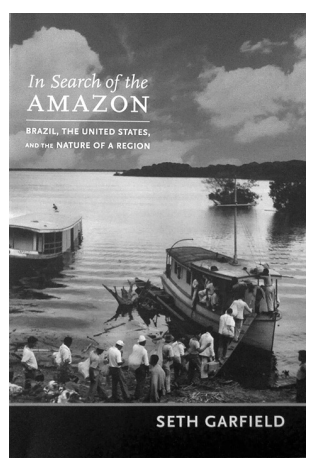

GARFIELD, Seth. In search of the Amazon: Brazil, the United States, and the nature of a region. Durham; London: Duke University Press. 2013. $368 p$.
T ançado nos EUA em 2013, In search of the Amazon é o segundo Ulivro do historiador Seth W. Garfield, professor do departamento de história da University of Texas at Austin. Garfield possui vários artigos lançados sobre temas que envolvem a Amazônia e a política indigenista brasileira na Era Vargas (1930-1945). Seu livro anterior foi traduzido para o português e lançado no Brasil em 2011 pela editora da Unesp com o título A luta indígena no coração do Brasil: política indigenista, a marcha para o oeste e os índios Xavante (1937-1988). O livro ora resenhado, no entanto, ainda não tem previsão de lançamento em português no Brasil.

In search of the Amazon analisa as redes constituídas por instituições, indivíduos, objetos e fenômenos no Brasil e EUA durante a Segunda Guerra Mundial que favoreceram uma série de processos que conformaram a paisagem amazônica e os modos de vida na região. Natureza e política não estão separadas nessa análise, que se constitui tanto como trabalho de história política quanto de história ambiental, embora o autor enfatize o seu afastamento em relação a referenciais teóricos da história ambiental. O aporte teórico-metodológico da obra baseia-se na noção de mediadores e redes compostas pela associação de humanos e não humanos, coprodutores de naturezas e sociedades. Tratase do conceito de agência dissolvida entre humanos e não humanos do sociólogo da ciência Bruno Latour. Ao longo de cinco capítulos, seguidos de um epílogo, seringueiros, seringalistas, políticos brasileiros, produtos manufaturados de borracha, flagelados da grande seca na região Nordeste de 1941-1943, agências estatais brasileiras e norte-americanas, indústrias de borracha sintética dos EUA, políticos em Washington e outros emergem na obra enquanto protagonistas das transformações sociais e ambientais na Amazônia durante a Batalha da Borracha (1942-1945). 
No primeiro capítulo é analisada uma conjunção de fatores de ordem interna e externa, que levaram o Estado brasileiro a realizar investimentos na Amazônia e adotar medidas visando à colonização e ao desenvolvimento econômico da região durante o Estado Novo (1937-1945). O aumento da demanda interna e externa por borracha devido ao estabelecimento de indústrias multinacionais de pneus em São Paulo e pela entrada dos EUA na Segunda Guerra Mundial foi entendido como uma nova oportunidade para a integração nacional da Amazônia. Longe de ser um objetivo novo, o autor aponta que a preocupação com o domínio estatal da região amazônica e sua transformação (de terra "selvagem" e abandonada para "civilizada" e fonte de riquezas para a nação) era uma questão antiga, já pensada e tentada ao longo dos séculos, desde o período colonial português. As principais diferenças das políticas implementadas pelo Estado Novo estavam na ênfase desenvolvimentista, que pregava a conquista da terra, o domínio das águas, a subjugação da floresta, ou seja, uma intervenção em larga escala para a reconstrução socioambiental da Amazônia.

Ainda no mesmo capítulo é destacado o papel de diversos agentes mobilizados pelo Estado visando à reconstrução da paisagem amazônica durante o Segundo Ciclo da Borracha. Oficiais militares, médicos sanitaristas, engenheiros, agrônomos, biólogos, geógrafos, literatos, cineastas e a máquina de propaganda do Estado Novo voltaram-se para a Amazônia, buscando sua remodelação material e imagética, dando caráter nacionalista à missão de seu desenvolvimento. O autor também destaca o papel das elites seringalistas no pacto oligárquico que, na prática, conformou os limites das políticas de Estado na Amazônia. Conhecedores do ecossistema local e associando essa condição à legitimidade política, as elites locais foram parte ativa no processo de transformação da paisagem amazônica.

O capítulo dois parte dos desdobramentos da drástica perda de suprimento de borracha dos EUA, com a invasão japonesa à península da Malásia, para analisar o histórico aumento da dependência social e política norte-americana a objetos feitos com látex. Essa dependência gerou a busca pela borracha da Amazônia e, ao mesmo tempo, intensificou diversos debates sobre modernidade e identidade nacional nos EUA. Contendo em torno de três mil peças de borracha, os automóveis ganharam cada vez mais espaço nos EUA ao longo das primeiras décadas do século XX, transformando as comunicações, a produção, o comércio, a saúde e a sexualidade dos indivíduos. A borracha, por meio do seu uso nos automóveis, tornou-se parte da vida humana, símbolo da modernidade e do progresso, além de ter fundamental importância na produção de material bélico. O início da Segunda Guerra Mundial gerou uma corrida pela estocagem de borracha por parte do governo norte-americano e da iniciativa privada das grandes empresas de borracha manufaturada, provocando tensões entre esses agentes. Diante da falta de suprimentos, as discussões no Congresso americano culminaram com a decisão de investir na importação de borracha vinda da Amazônia e no incentivo ao desenvolvimento de borracha sintética a partir de derivados do petróleo, de modo a acabar com a dependência externa. Em março de 1942, Brasil e EUA assinaram os "Acordos de Washington", prevendo diversos investimentos em infraestrutura, suporte técnico, sanitário e militar no país e em especial na Amazônia, em troca de suprir a demanda norte-americana e de apoio contra a Alemanha. Os acordos previam também reestruturar o sistema de trabalho nos seringais, buscando promover bem-estar social aos seringueiros, mas Garfield enfatiza 
como as elites amazônicas, além de políticos e empresários conservadores dos EUA buscaram frear quaisquer intervenções estatais nos meios de produção.

O terceiro capítulo analisa o esforço binacional de prover a mão de obra necessária para a extração de borracha na Amazônia e modificar qualitativamente o perfil do seringueiro e sua relação com o meio ambiente, de modo a aumentar a produtividade nos seringais. Apontada como indolente e fisicamente degenerada, a população da Amazônia era vista como inapta para maximizar a produtividade. Após debates e propostas entre o governo brasileiro e o norte-americano, optou-se mesmo pelo incentivo à migração de pessoas vindas do interior dos estados do Nordeste brasileiro, como aconteceu no Primeiro Ciclo da Borracha. O Serviço Especial de Mobilização de Trabalhadores para Amazônia (Semta) ficou encarregado de promover a migração, selecionando os trabalhadores de acordo com o biótipo e as condições de saúde, dando assistência aos migrantes durante o trânsito. O autor analisa as estratégias de mobilização com o uso das mídias (jornais, revistas ilustradas, cinema e rádio), o apoio dado pela Igreja católica e o surgimento da expressão "soldado da borracha", com a associação do seringueiro à defesa nacional brasileira e à liberdade do mundo diante da ameaça hitlerista. Garfield também analisa nesse capítulo o fracasso das tentativas dos governos brasileiro e norteamericano em padronizar as relações de trabalho nos seringais, que, na prática, mantiveram-se da mesma forma como ocorriam no Primeiro Ciclo da Borracha, por força das elites locais.

O capítulo quatro analisa, a partir das perspectivas política, social, econômica e cultural, as condições dos migrantes e famílias do interior do estado do Ceará e suas estratégias frente à grande seca de 1941-1943 e aos incentivos estatais de ida para a Amazônia. O autor destaca a crise econômica que se abateu sobre a região, as políticas públicas destinadas a minorar as condições de miséria das populações do interior, a ida de cearenses para a Amazônia, Minas Gerais e São Paulo, além do papel tanto dos incentivos estatais quanto das redes de transporte e informação na escolha dos migrantes pelo trabalho nos seringais. Cartas trocadas entre amigos e familiares, histórias de riquezas conquistadas e mortes trágicas durante o Primeiro Ciclo da Borracha, além da literatura de cordel, ajudaram na conformação do imaginário cearense sobre a floresta, levando muitos a optar pela longa travessia rumo aos seringais.

O último capítulo analisa como as autoridades brasileiras e norte-americanas, seringalistas e seringueiros, cada um com suas visões e projetos de poder, conformaram populações e paisagens na Amazônia. O Segundo Ciclo da Borracha favoreceu investimentos norteamericanos e brasileiros na região, dotando-a de infraestrutura, como aeroportos, rede de assistência à saúde nas principais cidades e políticas de bem-estar social. No entanto, os prejuízos advindos da suspensão dos trabalhos de extração no período de cheia dos rios, o fortalecimento das indústrias de borracha sintética e a própria dificuldade de intervir nos meios de produção na Amazônia levaram ao gradual rompimento dos acordos de cooperação por parte do governo dos EUA a partir de fins de 1943. Os seringalistas, remanescentes do Primeiro Ciclo da Borracha, economicamente conservadores e descrentes em relação ao discurso nacionalista do governo brasileiro, esforçaram-se por manter o antigo sistema de aviamentos, promoveram fraudes no sistema de crédito e contrabando, e desrespeitaram os contratos de trabalho assinados entre os seringueiros e órgãos do governo federal. Céticos de que o novo boom da borracha duraria, trabalharam para potencializar seus lucros, desafiando os ditames dos Estados e do mercado com o poder político advindo do controle da força de 
trabalho e do conhecimento que tinham do ambiente amazônico. Coube aos seringueiros desenvolver suas próprias estratégias individuais na floresta, o que incluiu o engajamento em outras atividades, a cobrança de indenizações na justiça e o uso do termo "soldado da borracha" na luta por reconhecimento e pensão na condição de ex-combatentes.

O epílogo analisa como o espaço amazônico foi sendo reconstruído em termos materiais e políticos nas décadas seguintes, especialmente durante o regime militar até a Conferência das Nações Unidas sobre o Meio Ambiente e Desenvolvimento, realizada no Rio de Janeiro em 1992. Garfield analisa brevemente como a Amazônia, novamente palco de projetos desenvolvimentistas durante o regime militar, virou alvo de atenção transnacional devido à emergência dos movimentos ambientalistas e da percepção de necessidade de conservação da floresta para evitar drásticas mudanças climáticas globais. Frente a esses movimentos transnacionais, os seringueiros tiveram a oportunidade de repensar suas identidades e formas de representação, aliando-as a práticas tradicionais que preservavam a floresta, em contraposição ao avanço da fronteira agrícola, que promovia a devastação, potencializando a violência e a marginalização dos extrativistas remanescentes.

Não é difícil para o pesquisador que trabalha com história da Amazônia e deseja utilizar a noção de agência dissolvida ou agenciamento recíproco entre humanos e não humanos conseguir empreender de fato esse modelo de análise. Trabalhar com história da Amazônia é vantajoso nesse sentido por ser difícil separar cultura e natureza nesse extenso espaço aquático e florestal (Leonardi, 1999, p.15). Nesse sentido, a obra de Garfield tem êxito em empreender uma análise que efetivamente combina associações que transgridem fronteiras entre o local, o nacional e o global, bem como o arcaico e o moderno, o social e o natural, seguindo os conselhos de Latour (1994) e lançando interessante contribuição para uma história ambiental transnacional (White, 1999). Justamente pelo esforço do autor em agregar diversos agentes conformadores das transformações da Amazônia durante o Segundo Ciclo da Borracha, emerge na leitura a pouca visibilidade dos povos indígenas em sua análise. As experiências desses povos foram fundamentais para o conhecimento que os seringalistas adquiriram do ambiente amazônico, possuindo intensa presença na sua conformação socioambiental (Ranzi, 2008, p.71-98).

O livro, no entanto, torna-se referência importante para pesquisadores que analisam tanto o Segundo Ciclo da Borracha quanto o primeiro, já que lança luz sobre as continuidades entre esses dois ciclos. De agradável e fácil leitura, também tem potencial de ser apreciado por leitores em geral, que se interessem pela história da Amazônia.

\section{REFERÊNCIAS}

LATOUR, Bruno.

Jamais fomos modernos: ensaio de antropologia simétrica. Rio de Janeiro: Editora 34. 1994.

LEONARDI, Victor.

Os historiadores e os rios: natureza e cultura na

Amazônia brasileira. Brasília: Paralelo 15; Editora UNB. 1999.
RANZI, Cleusa Maria Damo.

Raízes do Acre. Rio Branco: Edufac. 2008.

WHITE, Richard.

The nationalization of nature. The Journal of American History, v.83, n.3, p.976-986. 1999. 